\title{
A PRÁTICA SEXUAL E O ENVELHECIMENTO
}

\author{
Clícia Valim Côrtes Gradim¹, Ana Maria Magalhães Sousa², Juliana Magalhães Lobo²
}

RESUMO: Estudo qualitativo, descritivo e exploratório, com o objetivo de conhecer se a prática sexual é exercida em uma população de idosos; identificar fatores que interferem no relacionamento sexual homem e mulher; identificar quais estratégias são utilizadas por estes para continuarem a ser sexualmente ativos. Entrevistamos 18 idosos que participam da UNATI em Alfenas-MG. Mediante a análise de conteúdo temática identificamos três categorias: Envelhecer: da aceitação à insatisfação, em que o envelhecimento é enfrentado positivamente. $\mathrm{O}$ exercício da prática sexual, a menopausa, a disfunção eréctil, a rotina ou a falta de parceiros são fatores para o não exercício da mesma. A cultura, religião e a educação também influenciam na sexualidade. Enfrentamento para melhorar a vida sexual, o uso de estímulo visual e substituição do ato sexual por carícias. A prática sexual continua sendo exercida se o idoso tem condições físicas e parceiro. A sexualidade permanece em suas vidas, independentemente do ato sexual, por meio de carícias e trocas de afeto.

PALAVRAS-CHAVE: Envelhecimento; Sexualidade; Coito; Idoso.

\section{SEXUALITY PRACTICE AND AGING}

\begin{abstract}
Qualitative, descriptive, exploratory study objectifying: to know whether sexual practice is exercised among the elderly population; to identify factors that interfere in men's and women's sexual relationship; to identify which strategies are used by them to continue sexually active. Eighteen (18) elders, participants in UNATI - Alfenas, Minas Gerais State/ Brazil, were interviewed. Using the thematic content analysis, three categories were identified: aging - from acceptance to dissatisfaction - aging is positively coped. The exercise of sexuality, menopause, erectile dysfunction, routine or lack of a partner are contributors for not exercising it. Culture, religion and education also influence sexuality. Coping in order to improve sexual life - visual stimulus strategies and replacement of sex for affectionate touch were appointed. Sexual practice continues being exercised if the elderly are physically fit and have a partner. Sexuality remains in their lives, regardless the sexual act, by means of affectionate touch and affection exchanges.
\end{abstract}

KEYWORDS: Aging; Sexuality; Coitus; Aged.

\section{LA PRÁCTICA SEXUAL EN EL ENVEJECIMIENTO}

RESUMEN: Estudio cualitativo, descriptivo, exploratorio con el objetivo de saber si existe la práctica sexual en el envejecimiento; identificar factores que interfieren en la relación; y saber las estrategias que los ancianos utilizan a fin de seguir siendo sexualmente activos. Fueron entrevistados 18 ancianos que participan en UNATI-MG. Por medio del análisis de contenido temático, fueron identificadas tres categorías: Envejecer - de la aceptación a la insatisfacción: el envejecimiento es enfrentado positivamente por la mayoría. El ejercicio de la sexualidad con el envejecimiento - mujeres apuntan la menopausia, la rutina o falta de pareja como contribuyentes en las alteraciones sexuales; ya los hombres citan alteraciones de la frecuencia y erección. Enfrentamiento para mejorar la vida sexual: estrategias de estímulo visual y sustitución del sexo por la caricia fueron usadas. La práctica sexual continúa siendo ejercida si el anciano tiene condiciones físicas y pajera. La sexualidad permanece en sus vidas, independiente del acto sexual, como forma de caricia y cambios de afecto.

PALABRAS CLAVE: Envejecimiento; Sexualidad; Coito; Anciano.

${ }^{1}$ Professora Associada do Departamento de Enfermagem da Universidade Federal de Alfenas - UNIFAL-MG.
${ }^{2}$ Acadêmicas do Curso de Enfermagem da UNIFAL-MG.

Autor correspondente:

Clícia Valim Côrtes Gradim

Rua Gabriel Monteiro da Silva, 714 - CEP: 37130-000 - Alfenas-MG. Recebido em: 04/01/07

E-mail: cliciaqval@unifal-mg.edu.br 


\section{INTRODUÇ̃̃O}

A Organização Mundial de Saúde define como idoso, pessoas após os 60 anos, em países em desenvolvimento como o Brasil ${ }^{(1)}$. A velhice não tem idade definida para se iniciar; depende da disposição, atitude e interesse de cada pessoa em relação à qualidade de vida. Envelhecer não significa enfraquecer, ficar triste ou assexuado. Entretanto, em nossa cultura, diversos mitos e atitudes sociais são atribuídos às pessoas com idade avançada, principalmente os relacionados à sexualidade, dificultando a manifestação desta área em suas vidas.

As repercussões do processo de envelhecimento sobre a sexualidade constituem assunto particularmente repleto de preconceitos, "como se ela fosse atributo apenas do jovem em função de suas descobertas e do vigor físico"(2:111). Buscamos nas mudanças físicas que, embora normais e naturais, podem afetar o comportamento, a resposta sexual e os aspectos da sexualidade no envelhecimento.

No gênero masculino, dentre outras alterações na função sexual, as ereções espontâneas não acontecerão com a mesma rapidez e facilidade, e perderão parte da solidez da juventude. No gênero feminino, além das lentas mudanças da idade, a mulher experimenta a redução do hormônio sexual, o estrogênio, no momento da menopausa, passando por períodos de extremo desconforto. Os sintomas podem ser emocionais, como ansiedade, irritabilidade; e físicas, como ondas de calor, comas paredes vaginais podendo se tornar delgadas e lisas, levando a uma atrofia da mucosa vaginal e à diminuição da lubrificação da mesma. Em outras situações são os fatores psicológicos e/ou culturais que irão interferir ${ }^{(3)}$.

Todas essas mudanças inevitáveis do envelhecimento não necessariamente afetarão o prazer masculino e feminino, pois mesmo com estas alterações, os idosos poderão ser capazes de usufruir de uma relação sexual prolongada e o ato sexual pode se constituir em uma experiência sensual e prazerosa.

Além das mudanças físicas naturais, homens e mulheres, no processo de envelhecimento, estão mais susceptíveis a problemas de saúde como diabetes e hipertensão, que podem reduzir ou impedir o interesse pelas práticas sexuais, visto que a má circulação provocada por essas patologias influencia na libido sexual. Entretanto, se os idosos gozarem de boa saúde, não haverá impedimento para que o indivíduo mantenha atividade sexual, pois a função sexual existe até a morte e somente será diferente em cada época da vida ${ }^{(4)}$.

Nos dias atuais, fala-se muito sobre sexualidade, entretanto, sobre a prática sexual entre homens e mulheres no processo de envelhecimento pouco é discutido e, às vezes, até ignorado pelos profissionais de saúde e sociedade em geral. Assim, este estudo objetiva conhecer se a prática do ato sexual é exercida em uma população de idosos que utilizam a Universidade para a Terceira Idade (UNATI) no município de Alfenas-MG, identificar fatores que interferem no relacionamento homem e mulher ou entre parceiros e, identificar quais estratégias são utilizadas para continuarem a ser sexualmente ativos.

Os profissionais da saúde não têm como prática, em suas suas consultas, questionar sobre aspectos ligados à sexualidade e à prática sexual dos clientes, e menos ainda quando estes são idosos. Isso decorre porque a atenção à saúde é realizada com enfoque na queixa ou na doença. Também, não é verificado, na maioria das vezes, se medicamentos utilizados pelos pacientes interferem na prática sexual. No senso comum, é esperado que o término da prática sexual ocorra com o aumento da idade, e por isso não há questionamentos sobre práticas nesta área. Assim, muitas vezes, deixamos de abordar o (a) cliente sobre sua sexualidade, o que não permite a prevenção de patologias que têm aparecido nesta faixa etária, como a disfunção eréctil, o vaginismo, a dispareunia, o uso inadequado de certos medicamentos e a prevenção da Síndrome da Imunodeficiência Adquirida Humana, que tem aumentado na faixa etária de 60-69 anos no Estado de Minas Gerais ${ }^{(5)}$.

\section{METODOLOGIA}

O presente trabalho trata-se de uma pesquisa de abordagem metodológica qualitativa exploratória, realizada na Universidade da Terceira Idade da Universidade Federal de Alfenas-MG (UNIFAL-MG), no período de maio a julho de 2006.

O projeto de pesquisa foi aprovado pelo Comitê de Ética de Pesquisa da UNIFAL-MG, no processo ${ }^{\circ}$ 23087.000786/2006-5. Os princípios éticos da pesquisa envolvendo seres humanos foram seguidos de acordo com a Resolução 196/96 do Ministério da Saúde ${ }^{(8)}$.

Antes das entrevistas era explicado o objetivo da pesquisa, garantido o anonimato e a liberdade do participante de se retirar da pesquisa a qualquer momento, e após a assinatura do Termo de Consentimento Livre e Esclarecido as entrevistas eram realizadas. 
A coleta de dados foi realizada através de entrevista gravada, tendo como pergunta norteadora: Como é a sua prática sexual com o processo de envelhecimento? Ao responderem a primeira questão outras perguntas eram direcionadas para complementar a primeira. As entrevistas eram interrompidas quando havia a saturação de dados, ou seja, quando a repetição dos fatos se tornou freqüente. Os fatores de inclusão foram ter mais de 60 anos, não estar incapacitado física ou mentalmente e aceitar participar da pesquisa. Dos 18 atores sociais escolhidos, 12 eram do gênero feminino e seis do masculino, e a idade variou entre 60 a 79 anos. Os nomes são fictícios e foram escolhidos pelos participantes.

Utilizamos nessa pesquisa a técnica de análise temática, que consiste em descobrir os núcleos do sentido que compõem a comunicação e cuja presença ou freqüência de aparição pode significar algum dado para o objetivo analítico escolhido. A técnica funciona por operações de desmembramento do texto em unidades e em categorias, segundo reagrupamentos analógicos ${ }^{(6)}$.

O critério de categorização utilizado foi o semântico, em que todos os temas que possuem o mesmo significado ficam agrupados em uma mesma categoria. Estes possuem as seguintes qualidades, descritas por $\operatorname{Bardin}^{(7)}$ : a exclusão múltipla, a homogeneidade, a pertinência, a objetividade, a fidelidade e a produtividade. A análise dos dados procedeu-se nas seguintes fases: pré-analítica, em que definimos trechos significativos e categorias; fase de exploração do material, que abrange o tratamento dos resultados obtidos e a interpretação ${ }^{(7)}$.

Com as informações obtidas através do contato exaustivo com esse material, pudemos identificar as seguintes categorias temáticas: Envelhecer: da aceitação à insatisfação; o exercício da sexualidade com o envelhecimento e enfrentamento para melhorar a vida sexual.

\section{RESULTADOS E DISCUSSÃO}

A análise compreensiva das entrevistas possibilitou categorizar três unidades de significado que expressam a essência do estudo. Dessa forma, procuramos compreender a vivência do envelhecimento e da sexualidade nessa etapa da vida e os fatores relacionados a eles nas unidades seguintes:

\section{Envelhecer: da aceitação à insatisfação}

O processo de envelhecimento é único para cada ser humano, sendo uma experiência universal, progressiva e gradual. Desde o nascimento se envelhece um pouco, a cada dia. Trata-se de uma experiência diversificada entre os indivíduos, para a qual concorre uma multiplicidade de fatores de ordem genética, biológica, social, ambiental, psicológica e cultural. Diante desse processo, a pessoa idosa pode tomar diferentes atitudes e formas de ser e de se $\operatorname{comportar}^{(9)}$.

$\mathrm{O}$ decréscimo físico está presente em todo o processo da vida e não pode ser elemento único e exclusivo para caracterizar a velhice, pois o envelhecimento não se restringe a perdas. Na velhice há ganho de liberdade, acúmulo de experiência de vida, amadurecimento e sabedoria. Parte dos depoentes notou perdas com o envelhecimento, porém reconheceu aspectos positivos desse processo:

Envelhecer tem um lado que não é muito aceito, que a gente não quer perder o que é da juventude e tem um lado muito bom que é o de ficar mais madura, mais sábia, saber enfrentar melhor as situações, saber enxergar as coisas diferentes. Eu acho que isso ai supera a perda da parte física que quando a gente começa a ter as primeiras rugas, aquilo incomoda muito a gente. [...] eu aceito o meu envelhecer, porque eu tenho sessenta anos, mas eu acho que a minha cabeça é de quarenta, então eu estou satisfeita. A fisica não está ideal, eu já perdi muito, mas a mental eu ainda estou produtiva. Eu estou envelhecendo, mas não estou triste, estou muito feliz. Até acho que eu estou na melhor fase da minha vida" (Vovate, 60 anos).

Eu ainda não pus isto na cabeça, que envelheci [...]. Agora pelas fotos que eu vejo as antigas, 'o trem virou um bagaço'. O peito despenca, a nádega despenca, cai cabelo de onde não pode e nasce aonde não deve, é um desastre! Mas eu tenho as minhas qualidades, minha disposição, viajo muito, faço tudo sozinha [...]. Está aí o sessenta e seis, mas eu não sinto o peso dele (Maria Amélia, 66 anos).

Observamos que envelhecer não significa necessariamente acumular perdas e abandonar perspectivas. Existe o envelhecimento orgânico e suas conseqüências como as rugas, os cabelos brancos e a flacidez. O aparecimento de doenças decorrentes do desgaste físico, psíquico e social sofridos com o passar dos anos pode surgir. De modo geral, as pessoas não estão preparadas para aceitar e apreciar as mudanças que ocorrem com a idade, porque os padrões de beleza 
baseiam-se no corpo de jovem ${ }^{(10)}$.

Verificamos que as mulheres relatam o envelhecimento na perspectiva da estética, divulgada pela mídia, que reforça o olhar de gênero pelo qual elas devem ser jovens e bonitas, e o envelhecer mostra o oposto. Entretanto, o processo de envelhecimento do ser humano é real, como as rugas e os cabelos brancos, e as mulheres convivem com estas alterações ${ }^{(2,10)}$. Porém, entendemos que, por mais que o idoso não possua a vitalidade da juventude, por outro lado, ele tem o conhecimento adquirido com experiências ao longo de toda uma vida. Ao envelhecer, o homem adquire experiências e vivências riquíssimas que vão se acumulando. Notamos que os entrevistados têm consciência da ocorrência das mudanças em suas vidas com a chegada da idade e a maioria se adaptou bem a essas alterações.

O ciclo da vida é igual para todos os seres vivos: todos nascem, crescem, amadurecem, envelhecem e morrem. Dessa maneira, envelhecer é tão natural como qualquer outra fase da vida e as mudanças ocasionadas pelo envelhecer requerem adaptações e mudanças de hábitos, pois surgem novas situações e experiências ${ }^{(11)}$. Foram encontradas em alguns relatos considerações sobre essa naturalidade do processo de envelhecimento:

Envelhecer é uma coisa que depende do tempo [...] não é ruim. [...] todos têm que passar. Então, acho que é uma coisa normal. Nada que possa prejudicar a gente. A minha vida continua normalmente (Amélia, 74 anos).

Apreendemos que se essa fase da vida for encarada como uma evolução natural do desenvolvimento humano, e não como o declínio da vida, o enfrentamento e a adaptação frente às novas situações acarretadas pelo envelhecimento se tornam mais simples. Talvez seja necessário nessa etapa mudar comportamentos, adquirir novos hábitos e criar outras atitudes para se ajustar às novas circunstâncias ${ }^{(12)}$.

O que importa é a atitude diante da vida, a forma de ser e de buscar a própria felicidade. É possível viver esses anos, não como algo penoso e inevitável, mas como uma etapa prazerosa e, por que não, também com vitalidade. Evidenciam-se, a seguir, falas que emergiram nesse sentido:

Eu acho envelhecer muito importante. Eu acho que envelhecer é uma graça de Deus, porque é muito triste morrer cedo, sem ter feito nada, sem ter aproveitado a vida. Eu envelheci, muito tranqüilamente, aceito, assumo. Faço aquilo que está dentro das minhas possibilidades. Eu tenho uma vida, muito ativa, viajo bastante (Maria Augusta, 66 anos).

Eu fiquei mais velha [...] enrugadinha, cabelinho branco, mas eu não sinto que eu estou velha não. Tenho espirito de nova. Eu faço fisioterapia, hidroterapia, educação física (Ana, 70 anos).

Compreendemos as individualidades do envelhecer no momento em que nos deparamos com relatos de quem o vivencia de maneira positiva. Chamamos a atenção para os relatos de quem vive o envelhecimento ativamente e tem se dedicado a outras atividades. Talvez isso se explique porque, neste estudo, os idosos pertencem a um grupo da terceira idade e têm uma condição social e cultural que os permitem usufruir a vida de modo mais prazeroso. $\mathrm{Na}$ velhice, o lazer, as atividades físicas, uma vida equilibrada e com qualidade, mantêm vivos os interesses e objetivos e fazem com que essa etapa seja bem sucedida

Diante das várias transformações ocorridas no processo de envelhecimento, já mencionadas, tais como biológicas, psicológicas e sociais, percebemos que a aceitação da velhice depende de como o idoso lida com essas mudanças.

Observamos que esse grupo utiliza a Teoria da Atividade que vê o envelhecimento como a fase de perdas de certos papéis e, para compensá-las desenvolve-se outras habilidades, tendo uma velhice ativa e possibilitando viver a melhor fase da vida depois dos sessenta ${ }^{(13)}$.

\section{O exercício da sexualidade com o envelhecimento}

A sexualidade no envelhecimento é assunto que ainda é discutido por profissionais de saúde com certa parcimônia, não sendo possível generalizar sobre quais são as expectativas de homens e mulheres. No contato com os entrevistados, pudemos constatar experiências diferenciadas, satisfatórias e insatisfatórias, e condutas das mais variáveis possíveis.

Para compreender a sexualidade dos idosos, é preciso levar em conta que o comportamento sexual é definido por vários princípios: cultura, religião, educação, e estes valores influenciam intensamente $o$ desenvolvimento sexual, determinando como se irá vivenciá-lo e lidar com ele por toda a vida. 
As diferenças biológicas e psicológicas entre homens e mulheres são muito pequenas. Apesar disso, a sexualidade assume contornos e se expressa de maneira muito diversa, dependendo do fato de se ter nascido homem ou mulher. O jovem de 20 anos de idade, em função da necessidade de auto-afirmação, tem desempenho sexual mais intenso e nem sempre vai encontrar uma mulher, na mesma faixa etária, preparada psicologicamente para viver fortes emoções. Quando chegam aos quarenta, muitas mulheres vão se libertando de uma série de amarras, melhorando a auto-estima, e a função sexual passa a ser mais ativa depois dessa idade. Nessa fase, elas têm múltiplos orgasmos, enquanto os homens da mesma idade já não podem contar tantas vantagens ${ }^{(3)}$. Neste estudo observamos que essa diferença na sexualidade entre homens e mulheres foi mencionada por alguns dos entrevistados:

Parece que a vida está tão bela... Acho que eu sou a mesma coisa. Ele sim [...] no homem geralmente é difícil [...] às vezes ele toma um remédio e fica bonzinho [...]. Mas comigo não, comigo não tem erro não. Mas eu faço o que eu posso para ele, mas se não der certo, dá raiva. Dá vontade de tacar umas pesadas! Porque a gente está ali para aquele fim, então a gente quer que dê certo (Toninha, 71 anos).

Percebemos que algumas mulheres citam as dificuldades relacionadas ao ato sexual como sendo de ordem masculina. $\mathrm{O}$ uso de medicamentos capazes de superar os problemas de ereção não foi mencionado por depoentes masculinos mas sim por parceiras de homens que apresentam disfunção eréctil. Talvez para esses homens, que foram criados em uma sociedade machista que estimulava a virilidade, seja difícil admitir a necessidade de usar meios artificiais para conseguir o que eles sempre obtiveram naturalmente ${ }^{(14)}$.

$\mathrm{O}$ uso de medicamento para diminuir as disfunções eréteis, como o sildenafil, se tornou uma alternativa para muitos idosos contra as inseguranças na relação sexual, porém esse medicamento age no pênis, não no cérebro ${ }^{(15)}$. Mas, como o desejo, a necessidade do sexo e do orgasmo no homem diminuem com a idade, o uso deste medicamento nem sempre é eficaz.

Com o envelhecimento, o homem precisará de mais tempo para chegar ao orgasmo; será necessário um intervalo maior entre uma ejaculação e outra e o volume ejaculado será menor. Não haverá mais a mesma disposição física e a freqüência sexual se reduzirá. Essas alterações foram constatadas na quase totalidade dos depoimentos masculinos:

Quando eu era mais jovem, eu me relacionava sexualmente e, suponhamos, alguns minutos após eu completava o ato sexual. O orgasmo era completo. Até tinha a capacidade de segurar para que a parceira também sentisse satisfação... Hoje, eu não sou mais capaz de fazer isso. Quando a gente chega a fazer o ato sexual, dai a alguns instantes o membro não fica mais ereto. Isso não é só propaganda não, isso é verdade (Simão, 72 anos).

A potência piorou um pouco. Mudou muita coisa. A gente tinha mais desejo, praticava mais atos. Agora, de uma hora para cá, a gente vai diminuindo, vai chegando a um ponto que vai morrendo devagar (Toninho, 75 anos).

A fisiologia sexual masculina vai se alterando com o passar dos anos, é um processo natural do envelhecimento. Entretanto, existe a possibilidade de um homem apresentar ereção até os 80 anos ou mais, principalmente, se ele tiver uma boa saúde física e psicológica $^{(16)}$.

A diminuição do desejo sexual e do orgasmo, relatada no segundo depoimento, pode ser motivada pela insegurança de não conseguir uma ereção. Além dos bloqueios emocionais, também podem ocorrer outros impedimentos que interferem na resposta sexual, como doenças, ou o uso de medicamentos para tratálas. Embora o indivíduo seja capaz de manter o interesse pelo sexo até idade bem avançada, mesmo existindo a redução da atividade sexual com o passar do tempo, a libido e o desejo sexual são atemporais ${ }^{(17)}$.

Quando eu falo, a libido, éo tesão. Isso eu nunca perdi. Até escutar uma voz de uma pessoa me excita! Mas a freqüência diminui, porque o meu próprio organismo, meus braços, meus membros, tudo em mim hoje, ele está mais enfraquecido! Porque aí também hoje já advém a doença. Hoje eu faço uso de medicamentos que interferem na parte orgânica. Antes eu não tomava [...] hoje eu tomo cinco medicamentos (Lúcio, 61 anos).

Para que a função sexual se exprima de forma satisfatória e tranqüila, entendemos que é muito importante que o indivíduo tenha saúde, pois assim como existem doenças que interferem diretamente na 
prática sexual, determinados medicamentos também podem contribuir para uma vivência sexual difícil.

Tanto as modificações que ocorrem no corpo masculino como as que ocorrem no feminino fazem parte do processo normal de envelhecimento. Assim, como os homens na idade madura, as mulheres também percebem as alterações sexuais advindas da idade, embora com menos impacto no exercício sexual. É com a menopausa e as conseqüentes modificações hormonais que as mulheres sentem, às vezes, aparecer os primeiros problemas sexuais.

Com o declínio da produção de estrogênio, as mulheres, eventualmente, podem sentir sintomas como ondas de calor, suores frios, dores de cabeça, irritabilidade e depressão. Outras podem sentir a vagina ressecada e dispareunia, reclamam da pele e dos cabelos que se tornam mais secos, têm aceleração cardíaca e muita ansiedade ${ }^{(18)}$. Muitos desses sintomas foram revelados por grande parte das entrevistadas:

Sempre, com a passagem da idade, o organismo retrai um pouco, então, é um pouco mais doloroso. Então não é muito agradável, não. Com a menopausa, o organismo resseca, a gente não tem aquela quantidade de líquido lubrificante e a vagina fecha mais, mas, a idade não tem nada ver. Eu acho que hoje até a gente tem mais tranqüilidade, porque não tem aquela preocupação de gravidez. Eu acho que eu estou com a corda toda. Eu acho que eu sou a mesma de anos atrás. Eu tenho a mesma atração, o mesmo fogo. Sou muito viva ainda (Maria Augusta, 66 anos).

Existe um conceito social a respeito da menopausa de que a mulher, quando alcança esse período, perde o interesse e o prazer pelo sexo. Este mito é alimentado pela desinformação, "pelo preconceito machista contra a mulher e no processo de achatamento da mulher na sociedade"(19). Entretanto, as mesmas entrevistadas que observaram alterações com a menopausa expuseram que estas não foram suficientes para impedir que se relacionassem sexualmente e sentissem prazer sexual.

Diante do exposto, a perda da fertilidade na menopausa não pode ser confundida com a perda da sexualidade. O que acontece nessa fase diz respeito às mudanças dos órgãos de reprodução; a sexualidade e a capacidade de experimentar prazer sexual são atributos que duram a vida toda. As mulheres podem descobrir nessa fase uma nova liberdade, realizando a prática sexual mais livremente, sem correr o risco de uma gravidez indesejada ${ }^{(2)}$.

Depois da interrupção da menstruação, muitas mulheres se sentem menos femininas, menos sedutoras e vigorosas, e menos mulheres, fato relatado neste estudo:

Quando eu entrei [...] eu senti [...] uma tristeza e senti assim uma grande perda, como uma pessoa perde assim a beleza e a juventude de momento. Mas depois eu acordei, falei que não era, pensei assim que todo mundo passa, todo mundo passa por isso [...]. Eu sou o que eu sou hoje, eu acho normal (Juliana, 72 anos).

A gente já não é a mesma para fazer um strip-tease [...] a gente tem uma certa reserva. Não sinto mais à vontade como eu era quando eu era nova [...]. Que tinha o corpo tudo em cima, tudo certinho [...]. Agora, hoje não [...] está tudo caído (Maria Augusta, 66 anos).

Verificamos que os depoimentos emergem do sentimento de perda da feminilidade ou de não serem mais atraentes para o sexo oposto. Esses fatores estão relacionados com a estética e com a juventude, o que na cultura atual é extremamente valorizado para o gênero feminino. A sociedade valoriza a juventude física, e as mulheres se sentem inferiorizadas por receio de parecerem mais velhas e por não se encaixarem dentro desse padrão ${ }^{(20)}$. O corpo da mulher madura não tem a silhueta de uma mulher jovem, mas "é preciso se descobrir nesse corpo, mais flácido, com mais rugas, menos tônus e também ser feliz"(2:79).

Outros fatores foram relatados por mulheres como contribuintes para suas alterações sexuais, não ligados diretamente ao aspecto fisiológico e suas implicações. A rotina e a falta de estímulo no convívio do casal foram apontadas nessa fala:

Com a convivência, parece mais dois amigos, dois irmãos, porque vai envelhecendo junto. Não tem mais aquela vibração que tinha no começo [...] aquele amor, aquela coisa. Era muito tranqüilo, hoje é uma coisa razoável (Mariana, 64 anos).

A tendência entre os casais é o empobrecimento da vida sexual deixando que a sexualidade vá se tornando monótona, entediante e pouco excitante, transformando-se em companheirismo e intimidade, e a dimensão da troca sexual diminuiu; o que leva ao uso da expressão "virar irmão"(6,21). Compreendemos, porém, que a vida sexual é um reflexo dinâmico da vida das pessoas e épocas de interesse e desinteresse 
são totalmente normais e esperadas.

Identificamos que ocorrências externas comuns na velhice, como a falta de parceiro, também são colaboradoras para o declínio da vida sexual. A maioria das viúvas mencionou que, após o falecimento de seus maridos, não mais mantiveram relação sexual:

Eu fiquei viúva muito nova. Então eu [...] optei por criar meus filhos, dar educação para eles, deixei essa parte sentimental de lado. Não me fez falta não (Amélia, 74 anos).

Eu só conheci um homem [...] só conheci meu marido, então eu não sou capaz de entregar o corpo para outro. Não tenho vontade de conhecer homem nenhum. Não tive e nem quero. Estou bem assim (Joice, 75 anos).

Observamos que algumas mulheres foram educadas para ter um só parceiro e que a falta do mesmo, associada à idade, não as estimularam a procurar outro. Esse comportamento reafirma os aspectos culturais de gênero, de que a mulher consegue se realizar com os filhos e de que as necessidades sexuais são menores.

Algumas destacaram a dificuldade de encontrar um companheiro da mesma faixa etária. Como as mulheres tendem a viver mais anos que os homens, há mais viúvas que viúvos. Devido a seu maior número e também às influências da sociedade em que foram criadas, é especialmente difícil para essas mulheres encontrarem novos parceiros ${ }^{(22)}$. Entretanto, a opção de viver só pode estar relacionada também à insatisfação de relacionamentos anteriores.

A ausência de relacionamento sexual igualmente pode ser atribuída às mudanças fisiológicas do parceiro, levando-o a perder o interesse pelo ato sexual, fato que é tido como algo normal pela mulher:

Ele já mais idoso que eu, então ele já se acomodou. E ele acomodando, eu também me acomodei. O que não é procurado é esquecido. Então, já que ele não tinha esse incentivo para o ato, eu também não incentivei (Maria, 79 anos).

Por outro lado, não ter parceiro revela que a vida sexual é inexistente, por esse motivo é que a conquista de outro parceiro é tida como dificuldade, mas isso não impede que as mulheres tenham desejos sexuais:
Até hoje a gente ainda tem, mas não tem marido. Meu velho morreu, morreu cedo. E outro é dificil. É dificil arranjar um rapaz, um homem. Um homem que se case, que tenha responsabilidade, que ame assim uma senhora. Porque, às vezes, a gente sonha. Sonha que está [...] tem aquela coisa, aquela sensação (Celina, 60 anos).

Entendemos que ser só ou ser casado não tem necessariamente relação com o desejo sexual. Enquanto o segundo depoimento revela o desejo de manter uma vida amorosa e sexualmente ativa, mas define um perfil para um novo companheiro, o primeiro desvenda a acomodação da entrevistada diante da disfunção eréctil do parceiro. Esse fato é esperado nessa geração em que se admite o homem como tendo necessidades sexuais e as mulheres não, sendo que a aceitação desse fato ocorre sem problemas ${ }^{(21)}$.

Observamos que o primeiro relato é mais freqüente entre as mulheres mais idosas. Esse comportamento feminino relaciona-se à formação reprimida que tiveram. Nessa geração, a iniciativa da conquista, conforme o costume, cabia ao homem e, à mulher, a todo tempo saber conservar o seu valor ${ }^{(23)}$. As distinções entre os papéis de gêneros eram nítidas e a moral sexual fortemente diferenciada. Na prática, a moralidade favorecia as experiências sexuais masculinas, enquanto procurava restringir a sexualidade feminina ${ }^{(24)}$. Diante disso, não é de se surpreender que muitas mulheres não manifestem insatisfação perante a ausência do relacionamento sexual.

Em nome da manutenção da pureza das garotas, era comum que informações a respeito da sexualidade humana chegassem a elas marcadas por censuras, reservas, silêncios e preconceitos. Algumas das entrevistadas expressam em seus discursos esse sentimento:

O povo antigo não falava. A gente foi criada assim: a mãe da gente não contava nada para a gente, nem de menstruação, nem de nada. Você tinha que ficar sabendo quando chegava a hora. Para casar ninguém falava, ninguém sabia, a gente era muito boba. O povo antigo sofreu muito com tudo (Gabriela, 70 anos).

Antigamente, a mulher era muito tolhida. A mulher não podia fazer nada. A gente era muito censurada. Hoje não, hoje é tudo livre e eu concordo (Feliz, 69 anos). 
Como o povo de hoje não tem preconceito de nada, eu acho que mudou o jeito de viver. Antigamente a gente era assim mais resguardada, hoje não... A gente casava virgem, hoje não tem isso mais (Joice, 75 anos).

Apesar das repressões e da disparidade entre o tempo em que foram criadas e aquele em que convivem atualmente, percebemos que muitas mulheres maduras estão abertas para falar, conhecer e rever o tema da sexualidade. Falar sobre esse assunto nos dias atuais não parece ser tão inadequado como antigamente.

Algumas mulheres que se criaram nesse emaranhado de idéias rígidas e acompanharam passivamente essas transformações, conseguiram hoje superar os traumas da educação e foram capazes de estabelecer mudanças em seu comportamento sexual:

Eu sou de uma geração que foi criada com muito rigor [...]. Tudo era pecado [...]. Aos 20 anos [...] a gente faz sexo assim, a gente tem prazer, mais porque a carga hormonal é grande [...] mas o sexo que eu tenho agora é estrondoso [...]. Eu achava que eu não era capaz mais defazer sexo bem [...]. Mas agora [...] eu descobri que eu estou apta, eu não sabia que eu estava tanto [...]. Só que devido às minhas repressões [...] eu levei até quatro anos para fazer determinadas coisas no sexo [...]. Então agora eu estou livre disso e tendo um companheiro que seja assim bem estimulante [...] eu descobri que eu estou no ápice da minha vida sexual (Vovate, 60 anos).

Observamos que o envelhecimento para essa mulher foi um fator que permitiu realizar quebras de seus conceitos e fazer uma reconstrução da sua sexualidade. A repressão limita excessivamente a possibilidade de conhecimento e auto-conhecimento nessa esfera ${ }^{(6)}$. Acreditamos, porém, que a sexualidade do idoso é rica de várias formas e gratificante, de maneira que até mesmo eles se surpreendem quando a desvendam.

Dentro dessa categoria, pudemos evidenciar diversos fatores, tais como envelhecimento físico, uso de medicamentos e ausência de parceiros que contribuem para que as alterações sexuais ocorram com o envelhecimento. Elas podem influenciar, positiva ou negativamente, de acordo com as particularidades de como cada um encara a sua sexualidade que pode ser construída e reconstruída em vários momentos da vida.

\section{Melhorando a vida sexual}

A idéia de que as pessoas perdem suas habilidades sexuais à medida que envelhecem não passa de um conceito errôneo. A verdade é que a prática sexual, assim como várias atividades, pode se tornar menos valorizadas com a idade ${ }^{(13)}$. O fato de haver uma diminuição das freqüências nas atividades sexuais não significa fim da expressão ou do desejo sexual.

Diante das particularidades na sexualidade de cada ator social entrevistado, pudemos averiguar diferentes estratégias utilizadas por eles para melhorar a sua vida sexual. Percebemos que parte deles na tentativa de melhorar a qualidade, buscou novos meios para a relação sexual, como estratégias de estímulo visual por meio de literatura ou buscando esse tipo de estratégia com parceiros mais jovens:

Hoje em dia todo mundo lê e até eu procuro ler as revistas Kama Sutra da vida [...]. Procurar as posições boas [...] sair da rotina. Então a gente está sempre fazendo novidades [...]. E ele teve paciência comigo. Eu estou com um companheiro de quarenta e cinco anos [...] que me considera uma menina de quinze [...] que valoriza o meu corpo, a minha cor, a minha cabeça, a minha conversa (Vovate, 60 anos).

Uma vez eu comprei uma revistinha de posições diferentes, eu tentei fazer isso, mas para mim não alterou nada. E para ela também. Se ela quisesse, sentisse mais prazer fazendo uma posição diferente eu fazia [...]. Eu acho que ela prefere fazer de uma maneira mais cômoda, então eu também. Eu só tentei uma vez variar, para ver se ficava mais interessante. Eu tenho aí uma namoradinha [...] de vez enquanto eu encontro com ela. Ela é jovem [...] ela é diferente da minha esposa [...] já gosta mais de extravagância. Gosta de fazer posições diferentes (Márcio, 62 anos).

Notamos que as pessoas idosas também são capazes de colocar múltiplas facetas da sexualidade dentro da própria vida erótica, acrescentando um sabor novo e especial à prática sexual. No primeiro depoimento, verificamos a satisfação da entrevistada no uso de estratégias no relacionamento com um parceiro mais jovem. $\mathrm{O}$ segundo relato evidenciou a tentativa de adicioná-las no relacionamento conjugal, sem a receptividade da esposa. Diante disso, ele procurou implementá-la em um relacionamento extraconjugal com uma mulher mais jovem. Talvez os 
parceiros mais jovens estimulem os mais velhos a buscarem inovações nas práticas sexuais.

Entretanto, a sexualidade está além do impulso e do ato sexual e, para muitas pessoas, ela oferece a oportunidade de expressar estima, afeto, lealdade e traz consigo a possibilidade de emoção, ternura e romance $^{(25)}$. Sair da prática sexual para a vivência da sexualidade plena exige o cultivo da intimidade, a busca de informações corretas que não se encontram em revistas populares, filmes eróticos e coisas semelhantes.

O desejo, a excitação e o orgasmo, de uma forma mais ampla, possuem características psicológicas, visuais e táteis e não necessariamente genitalizadas, facilitando assim, a continuidade do encontro amoroso que pode ser vivenciado durante toda vida do ser humano, independentemente de sua idade.

Temos uma necessidade inata em trocar gestos de amor expressando por meio da compreensão, do interesse mútuo, da empatia, do toque, das carícias, de palavras afetuosas e de atenção. Na velhice, essa troca assume uma importância maior. À medida que o corpo não responde mais ao desejo, as adaptações sexuais se tornam necessárias e ajudam na sexualidade. Alguns homens, na velhice, lançam mão de táticas para substituir a prática sexual, como fica evidenciado nos relatos a seguir:

Adoro beijar! Beijar e abraçar [...] abraçar é mais gostoso até do que beijar! Um abraço carinhoso vale tanto! Uma mulher que dá um abraço gostoso vale mais do que ir para a cama. Chega certa idade que você tem que substituir o sexo pelo carinho, pelo companheirismo (Lúcio, 61 anos).

É bom fazer, mas também se não rolar, também não está me alterando absolutamente nada, psiquicamente falando. Porque sempre o carinho vai haver [...]. Quer dizer, sempre o beijo, o passar a mão, enfim [...] o abraço, tudo isso vale tanto quanto o ato sexual (Simão, 72 anos).

Entendemos, aqui, que a sexualidade não é expressa somente no ato sexual. Ela flui naturalmente na vida de qualquer pessoa e é marcada pela intimidade, pelo amor, pelo carinho e pela doação. Com o envelhecimento, os sentimentos que marcam os tempos do namoro devem ser resgatados: companheirismo, cumplicidade e contato físico, por intermédio do toque, do abraço, das carícias e do beijo ${ }^{(25)}$.

As alterações que ocorrem no envelhecimento podem até incapacitar para o ato sexual, mas oferecem oportunidade para que o idoso descubra novos caminhos de sua sexualidade e a vivencie até a morte.

\section{CONSIDERAÇOES FINAIS}

O envelhecimento é um processo natural da vida, mas traz consigo potencialidades únicas e distintas de cada pessoa. Observamos neste estudo que as perdas, como o decréscimo físico e o surgimento de doenças, ocorreram, mas houve adaptação diante dessas alterações, além do reconhecimento de aspectos positivos desse processo como o ganho de experiências e de liberdade.

Observamos que o envelhecimento não implica um estagnar da sexualidade, como os resultados deste estudo mostram. Apesar de existirem idosos que não têm relações sexuais, existe um maior número deles que continua a exercê-la por apresentar condições físicas e possuir parceiro. Os que não a exercem relatam exprimir a sua sexualidade por meio de carícias e trocas de afeto, o que lhes é ternamente agradável nesta etapa da vida.

As mulheres referiram o modo com que foram criadas e algumas conseguiram reconstruir a sua vida sexual, mesmo após a perda do companheiro. No entanto, outras mulheres optaram pela criação dos filhos, papel esperado para a mulher na sociedade brasileira. Os homens relataram que houve um decréscimo na sua vida sexual, apontaram a disfunção eréctil como a maior dificuldade, mas que isso não os impediu de desejarem suas companheiras. A falta de parceiro foi citada pelos idosos que não mantêm relação sexual, e a acomodação da vida sexual foi mencionada dentre os que têm parceiros há longo tempo. $\mathrm{Na}$ tentativa de aprimorar as relações sexuais, poucos relataram a busca de meios para melhorar a qualidade do relacionamento sexual, sendo este bem sucedido somente quando a decisão foi do casal.

Como a sociedade tem se modificado rapidamente e a população de idosos vem aumentando gradativamente, estudos dentro desta área devem continuar, porque observamos que a prática sexual é exercida por aqueles que têm condições físicas independentemente da idade; e que as mulheres relatam ter necessidades sexuais, mostrando que a menopausa não é o marco final de sua vida sexual.

É importante que o profissional da saúde se eduque em abordar questões da sexualidade com os clientes idosos, permitindo um espaço para que os 
mesmos sintam confiança e possam adquirir conhecimentos, tirar dúvidas para que passem por essa etapa com qualidade de vida sexual.

\section{REFERÊNCIAS}

1 Brasil. Plano de ação internacional para o envelhecimento. In: Assembléia Mundial do envelhecimento. 2002; Abril 8-12; Madri: ONU.

2 Costa M. Mulher: a conquista da liberdade e do prazer. Rio de Janeiro: Prestígio; 2004.

3 Rosenthal SH. Sexo depois dos 40. Rio de Janeiro: Ediouro; 2004.

4 Almeida AB. Climatério. Porto Alegre: Artes Médicas; 1993.

5 Ribeiro L, Jesus M. Avaliando a incidência dos casos notificados de AIDS em idosos no estado de Minas Gerais no período de 1999 a 2004. Cogitare Enferm. 2006;11:(19)12.

6 Minayo, MCS. O desafio do conhecimento: pesquisa qualitativa em saúde. $2^{\mathrm{a}}$ ed. São Paulo: Hucitec; 1993.

7 Bardin L. Análise de conteúdo. Lisboa: Edições 70; 2004.

8 Ministério da Saúde (BR). Conselho Nacional de Saúde. Diretrizes e normas regulamentadoras de pesquisa em seres humanos. Resolução ${ }^{\circ} 196$, de 10 de Outubro de 1996. Brasília; 1996.

9 Ferrari MA. O envelhecer no Brasil. O mundo da saúde. 1999;23(23):197-203.

10 Fraiman, AP. Sexo e afeto na terceira idade. São Paulo: Gente; 1994.

11 Almeida ACG. Movimento de idoso. Rev Vida Saúde. 2005;67(1):36-9.

12 Zimerman GI. Velhice: aspectos biopsicossociais. Porto Alegre: Artmed; 2000.

13 Alves, AM. Família, sexualidade e velhice feminina. In: Heilborn ML, Duarte LFD, Peixoto C, Barros ML, organizadores. Sexualidade, família e ethos religioso. Rio de Janeiro: Garamond; 2005.

14 Gradim CVC. Sexualidade de casais que vivenciaram o câncer de mama [tese]. Ribeirão Preto (SP): Universidade de São Paulo; 2005.
15 Morgentaler A. O mito viagra: o surpreendente impacto no amor e nos relacionamentos. Rio de janeiro: Ediouro; 2004.

16 Risman, A. Sexualidade e o homem idoso. Arq Geriatr Gerontol. 1996;0(1):123-4.

17 Azevedo JRD. Ficar jovem leva tempo: um guia para viver melhor. São Paulo: Saraiva; 1998.

18 Patrizzi LJ. Um certo clima. Rev Vida Saúde. 2004; 66(9):18-20.

19 Paiva, JR. Atividade sexual e envelhecimento humano. São Paulo, 1999, junho. Disponível em http:। www.prosex.org.br.

20 Ferreira TF. A cultura da menopausa. Nursing. 2006;94(9):724-7.

21 Heilborn, ML. Dois é par: gênero e identidade sexual em contexto igualitário. Rio de Janeiro: Garamond; 2004.

22 Pérgola F. La sexualidad en la senescencia. Rev Assoc Med Argent Buenos Aires. 2004;117(2):34-9.

23 Bassanezi, C. Mulheres dos anos dourados. In: Priore, M. História das mulheres no Brasil. São Paulo: Contexto; 2002.

24 Marques B. Íntimo e especial. Rev Vida Saúde. 2002a; 64(3):48-9.

25 Vasconcellos D, Novo RF, Castro OP, Vion-Dury K, Ruschel A, Couto MCPP et al. A sexualidade no processo do envelhecimento: novas perspectivas comparação transcultural. Est Psicol. 2004; 9(3):413-9. 